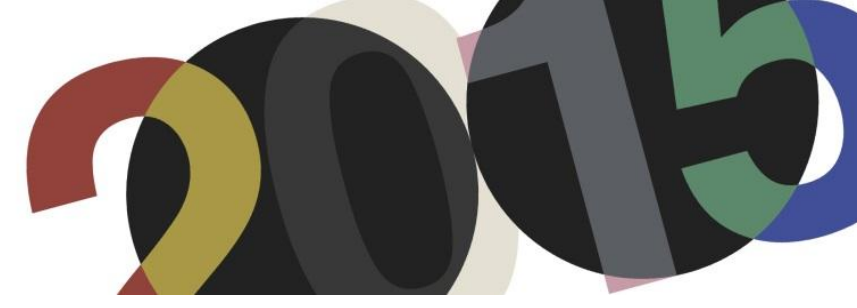

DOI: http://dx.doi.org/10.4995/LC2015.2015.554

\title{
El dibujo y la noción de horizonte en Le Corbusier
}

\author{
G. Hidalgo Hermosilla
}

\author{
Pontificia Universidad Católica de Chile
}

\begin{abstract}
Resumen: Este trabajo indaga en la particular forma de dibujar la arquitectura de Le Corbusier: una síntesis de distintas tradiciones gráficas que adquirió en su juventud y que fue capaz de integrar coherentemente en un estilo muy personal. Intentándola definir, William J. R. Curtis lo asimiló a un sistema de apuntes taquigráficos y la consideró dotada de un poder alquímico. Es un hecho que esta forma de dibujar abrió una vía fecunda de aproximación a la arquitectura, tanto para estudiarla como para generarla. En este trabajo intentamos precisar una de sus cualidades: la capacidad de situar, que se verifica a partir de la noción de horizonte. Como se sabe, el concepto de horizonte tomó una forma precisa con el surgimiento de la perspectiva renacentista, pero que en el caso de Le Corbusier es reformulada a partir de sus primeras experiencias con las visiones amplias, paisajísticas, elevándolo a referencia fundamental del hombre en el mundo, remitiéndolo por tanto a dimensiones históricas, culturales, existenciales.
\end{abstract}

Abstract: This paper explores the particular way of drawing the architecture Le Corbusier: a synthesis of different graphic traditions acquired in his youth and which he was able to integrate coherently in a very personal style. Trying to define his way of drawing, William JR Curtis assimilated it to a system of shorthand notes and considered it equipped with an alchemical power. It is a fact that this way of drawing opened a fruitful approach to studying and generating architecture. This paper attempts to clarify one of his qualities: the ability to situate, putting into play the notion of horizon. As it is known, the concept took its precise form with the emergence of Renaissance perspective, but in the case of Le Corbusier it was reformulated from his first experiences with the panoramic views, raising it to the fundamental reference of the relationship of man and world, and thus returning it to historical, cultural and existential dimensions.

Palabras clave: Le Corbusier; Dibujo; Horizonte.

Keywords: Le Corbusier; Drawing; Horizon.

\section{Introducción}

La particular forma en que Le Cobusier llegó a dibujar la arquitectura se puede rastrear, paso a paso, gracias a la extraordinaria cantidad de documentación que dejó, ya sean estos escritos, cartas, y por supuesto los mismos dibujos. Después de que todo este material fue convenientemente catalogado, se dispuso de una vía expedita para estudiar y analizar sus dibujos, particularmente aquellos de su juventud ${ }^{1}$. No son pocos los antecedentes que dan cuenta del origen de esta manera de dibujar. En la base de todo está su formación en la Escuela de Arte de La Chaux-de-Fonds y la innegable influencia de su maestro Charles L’Eplattenier y, a través de éste, del crítico inglés John Ruskin ${ }^{2}$. Posteriormente, se suma a este proceso su propia autoformación que abarcó una amplitud

\footnotetext{
${ }^{1}$ Uno de los primeros trabajos exhaustivos de catalogación de los dibujos juveniles de Le Corbusier fue el realizado por: Seckler, Mary Patricia May. The Early Drawing of Charles-Édouard Jeanneret (Le Corbusier) 1902-1908. New York and London: Garland Publishing, 1977.

${ }^{2}$ Hidalgo, Germán. "La constatación de un aprendizaje. El viaje a Italia de 1907 de Ch-É. Jeanneret”. Massilia, Annuaire d'Etudes Corbuseennes. Sant Cugat del Vallés: Associacio d'Idees, Centre d'Investigacions Estètiques, 2008, pp. 04-30.
} 
de ámbitos, y un vivo interés por los temas y problemas propios de su época. Todo ello fue decantando en una forma particular de dibujar, en la que es posible detectar estos componentes originales ${ }^{3}$.

Tanto la observación atenta como la disciplina misma del dibujo, no pueden comprenderse al margen de los preceptos ruskinianos que dominaron completamente su primera formación en el seno de su ciudad natal ${ }^{4}$. Del mismo modo que la síntesis lograda en los dibujos de su viaje a Oriente no puede entenderse sin el trasfondo del postimpresionismo de Paul Signac, por mencionar a uno de los artistas que en aquella época seguía con real interés y admiración ${ }^{5}$. Las implicancias de este complejo proceso de formación quedan a la vista con nitidez si se comparan los dibujos que realizó en los dos viajes más importantes de aquella época: el de Italia de 1907 y el de Oriente de 1911, en los que podemos identificar dos momentos claramente diferenciados.
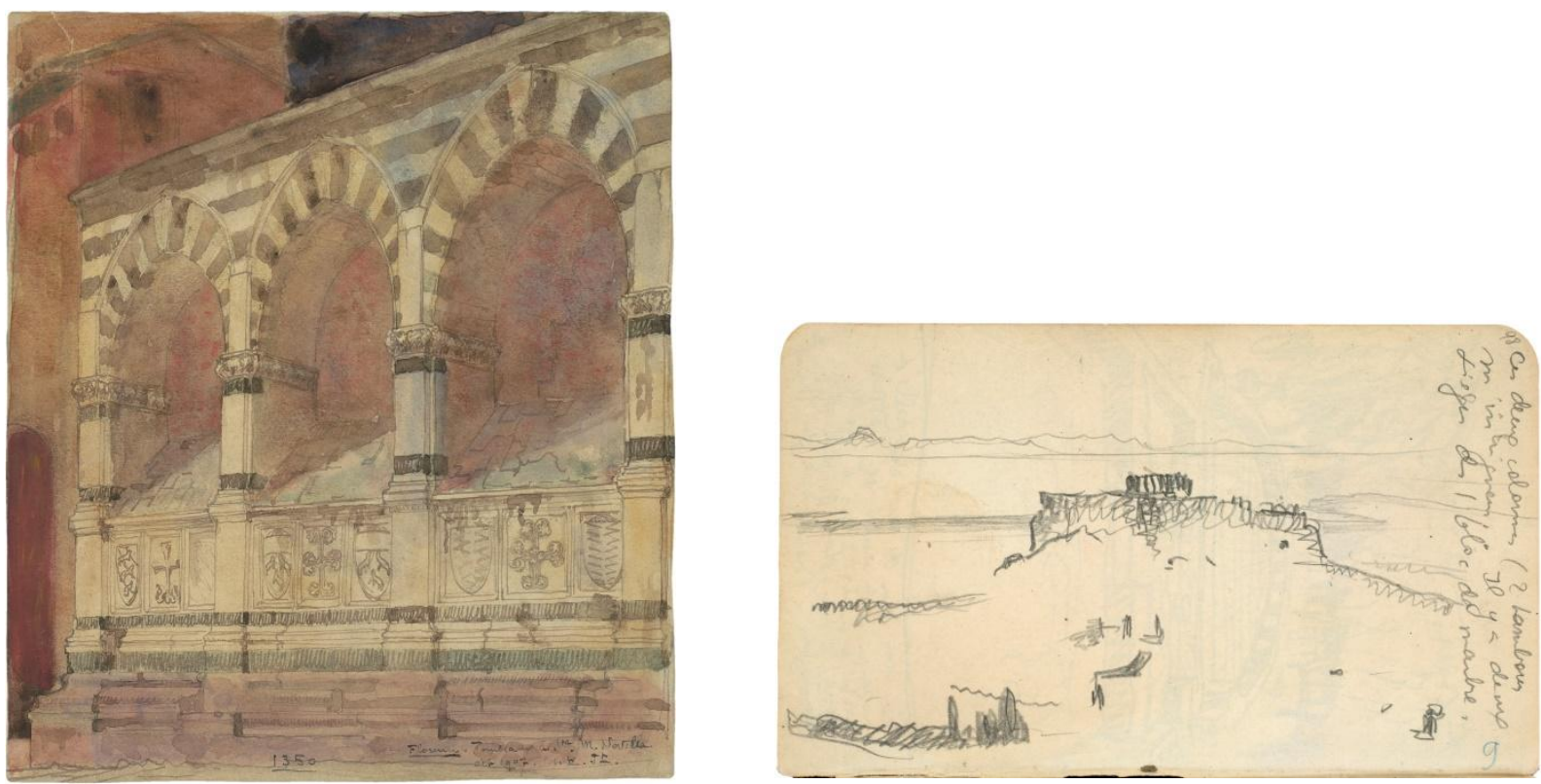

1. Izquierda. Ch-É. Jeanneret. Santa Maria Novella, sarcófagos del muro del patio de ingreso, Florencia, 8 de octubre de 1907. Derecha. Ch-É. Jeanneret. La Acrópolis vista desde el Monte Licabeto. 1911.

En relación a estos antecedentes cabe preguntarse: cómo se puede explicar que Ch-É. Jeanneret, Le Corbusier, dibujara así en el viaje de 1907 (Figura 1. Izquierda), y cuatro años después, en el viaje a Oriente, dibujara de esta otra manera (Figura 1. Derecha). ¿Qué pasó en esos cuatro años?

\footnotetext{
${ }^{3}$ Hidalgo, Germán. La Arquitectura del Croquis. Dibujos de Ch-E. Jeanneret en Italia 1907 y en Oriente 1911. Un estudio de sus antecedentes. Universidad Politécnica de Cataluña, Escuela Técnica Superior de Arquitectura de Barcelona, Departamento de Composición, 2000. Tesis doctoral inédita.

${ }^{4}$ La visión de Ruskin sobre el dibujo la encontramos sintetizada en: Ruskin, John. The Elements of Drawing. London: George Allen, 1856. Traducción Española: Técnicas de dibujo. Barcelona: Editorial Leartes, 1999.

${ }^{5}$ Hidalgo, Germán. La Arquitectura del Croquis. Op. cit., pp. 371-380.
} 


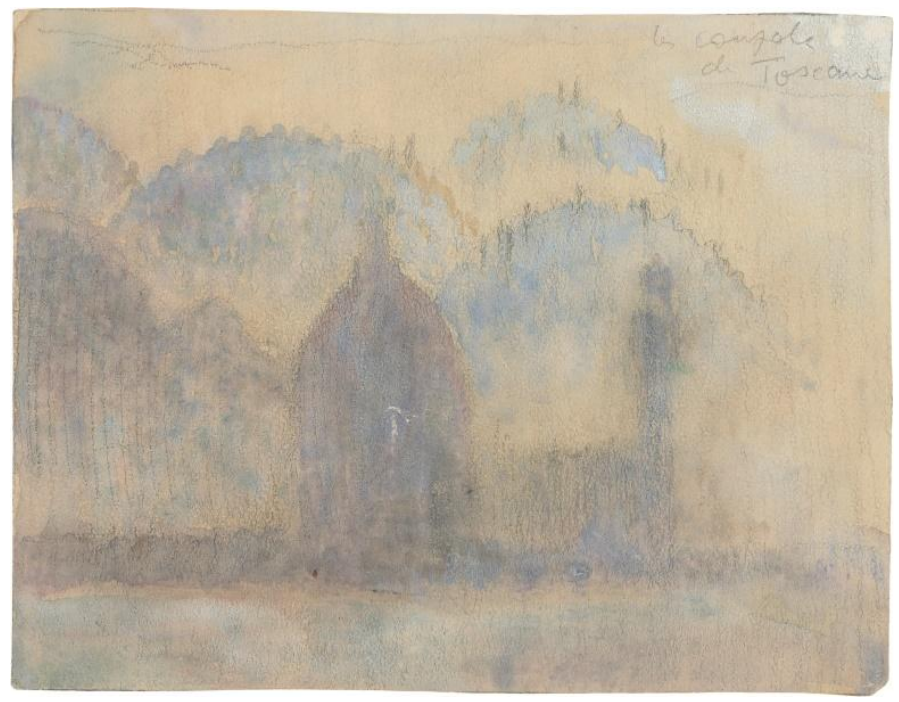

2. Ch-E. Jeanneret. Santa Maria de las Flores, Florencia, 1907.

Un tercer dibujo suyo nos puede ayudar a entender qué ocurrió en este proceso (Figura 2). Este tercer dibujo, es al igual que el primero una acuarela, y también fue realizada en 1907, en la misma ciudad de Florencia. Sin embargo, fue hecha cuando su autor concluye la visita y deja la ciudad, es decir, cuando se va. E irse, como todos sabemos, no es lo mismo que llegar. En efecto, cuando Jeanneret dejó Florencia, él mismo lo escribe en una sus cartas a L’Eplattenier, ya había aprendido ${ }^{6}$ ¿ ¿Qué aprendió Jeanneret en ese viaje, y qué relación tiene este aprendizaje con esta acuarela y con el problema que nos ocupa?

A juzgar por el talante de la primera acuarela, aprendió que una representación no tiene por qué ser tan detallada. Es más, fue la urgencia de realizarla la que lo llevó a tomar de lo visto sólo lo esencial: la acuarela fue hecha desde el tren, cuando Jeanneret se iba. Segundo, y como un modo de asegurarse, aprendió que lo visto como esencial, había que enfatizarlo en el dibujo, de modo de no dejar lugar a dudas con respecto a lo observado. Tercero, que la distancia es buena consejera: era bueno ver de nuevo, otra vez, desde lejos, aquello que desde cerca no le había revelado sus secretos. Cuarto, y esto quizás sin que él mismo lo supiera en ese instante: que para comprender algo debemos encontrar la posición correcta; aquella posición desde donde las mismas cosas que ya hemos visto toman un nuevo sentido. Así, desde esta posición, el tren en donde él mismo viajaba, la cúpula de la catedral, el campanil de Giotto y las colinas cercanas y lejanas, coinciden, se alinean en el dibujo.

Esta observación, que en el viaje de 1907 se le revela por primera vez, cuatro años más tarde madurará y tendrá su confirmación. En efecto, en el dibujo de la Acrópolis de Atenas de 1911 ya es plenamente consciente. Y para demostrar su real trascendencia, Le Corbusier siguió escribiendo sobre ella, no una sino muchas veces.

Por ejemplo, en "Tres advertencias a los señores arquitectos III. El Plan", la describirá con mucha precisión y claridad. Justamente, a los pies de una imagen de la planta de la Acrópolis de Atenas anotó: "El desorden aparente del plan sólo engaña al profano. El equilibrio no es mezquino. Está determinado por el famoso paisaje

\footnotetext{
${ }^{6}$ Carta de Ch-É. Jeanneret a su maestro Charles L’Eplattenier, 1 de noviembre de 1907. Le Corbusier. Il Viaggio in Toscana (1907). Venecia: Cataloghi Marsilio, 1987, pp. 136-137. "He aprendido por qué los florentinos han deseado tener en su catedral la cosa más noble y más grande que se puede hacer y que ha sido hecha. Así la he visto desde el tren, a lo largo de cuatro distintas oportunidades y cada vez en la neblina matutina, y icaray, debí ser verdaderamente torpe para no comprender". Identificamos en esta declaración un símil de lo que muestra la acuarela de la catedral de Florencia, vista desde la distancia. Se debe destacar su carácter único, sin igual entre las que realizó en aquel viaje.
} 
que se extiende desde el Pireo al Monte Pentélico. El plan está concebido para una visión lejana: los ejes siguen el valle y las falsas escuadras son habilidades del gran director de escena. La Acrópolis sobre su roca y sus muros de sostén, se ve desde lejos, en forma total. Sus edificios se amontonan en la sucesión de sus múltiples planos"'.

En su libro El Viaje de Oriente, dice algo similar: "Un día. Alguna tarde, desde la falda del Licabete que domina la Acrópolis, he visto más allá de la ciudad moderna encendiendo sus luces, la colina desamparada, y su vigía de mármol el Partenón, dominándola para conducirla, parecía, hacia el Pireo, al mar que fue esa vía vibrante a través de la cual tantos tesoros conquistados vinieron a alinearse bajo los pórticos de los templos" ${ }^{\prime 8}$.

Y cuando habla directamente sobre el "eje", lo confirma en forma elocuente: "El eje de la Acrópolis va del Pireo al Pentélico. Del mar a la montaña, de los Propileos, perpendiculares al eje, a la lejanía del horizonte, al mar. Horizontal perpendicular a la dirección que os ha impuesto la arquitectura en el lugar donde estáis, percepción ortogonal que hay que tener en cuenta. Alta arquitectura: la Acrópolis extiende sus efectos hasta el horizonte. Los propileos en el otro sentido, la estatua colosal de Atenea en el eje, y el Pentélico al fondo. Eso importa".

Estos breves textos contienen y dan forma a una de las observaciones más potentes de Le Corbusier, podría decirse capital para lo que llegó a ser el grueso de su obra arquitectónica. Ella se organiza en torno a un elemento bien específico: el eje que va desde el Pireo al Monte Pentélico, pasando por la Acrópolis y por el mismo Monte Licabete desde el cual había dibujado los templos, oportunidad cuando había encontrado, otra vez, un punto preciso para dibujar y hacer "coincidir" naturaleza y arquitectura.

La primera conclusión que dejan estos dibujos es que para producir este encaje entre naturaleza y arquitectura era necesario establecer un distanciamiento. La segunda, que la arquitectura no se puede ver, ni apreciar, desde una corta distancia, por lo cual la mirada amplia se impone como requisito ${ }^{10}$. Josep Quetglas demostró cómo Le Corbusier armó algunas vistas interiores de la Villa Savoye, a partir de la adición de sucesivas perspectivas cónicas convencionales, de $60^{\circ}$ de apertura, ampliando el cono visual y la capacidad de ver del ojo, al extremar su horizontalidad. Según Quetglas, se trataba de "algo que sólo puede provenir de la mirada y de la agudeza escenográfica de Le Corbusier: me refiero a la ampliación del encuadre hacia la izquierda, que incluye el parque en la escena y que cambia la dirección y calidad de la mirada [...] Esta heterogeneidad del espacio percibido, que corta en dos el ángulo de visión, es una de las características más íntimas y constantes de la mirada de Le Corbusier" ". Por último, los dibujos introducen claramente la noción de horizonte como un factor decisivo en la comprensión del hecho observado.

\section{La noción de horizonte en Le Corbusier}

Una primera cuestión que se debe abordar, es saber si la idea de horizonte estaba presente efectivamente en el pensamiento de Le Corbusier y de qué manera, para luego tratar de explicar qué entendía por ésta.

\footnotetext{
${ }^{7}$ Le Corbusier. Hacia una arquitectura. Barcelona: Editorial Apóstrofe, 1998, p. 39.

${ }^{8}$ Jeanneret, Charles-Édouard (Le Corbusier). El Viaje de Oriente. Murcia: Colegio Oficial de Aparejadores y Arquitectos Técnicos. Librería Yerba, 1993, p. 183.

${ }^{9}$ Jeanneret, Charles-Edouard (Le Corbusier). Op. cit., p. 151.

${ }^{10}$ Monsteys, Xavier. "El hombre que veía amplios horizontes: Le Corbusier el paisaje y la tierra”. En Massilia, Annuaire d'Etudes Corbuseennes. Sant Cugat del Vallés: Associacio d'Idees, Centre d'Investigacions Estètiques, 2004 (bis). pp. 06-21.

${ }^{11}$ Quetglas, Josep. Les Heures Claires. Proyecto y arquitectura en la Villa Savoye de Le Corbusier y Pierre Jeanneret. Sant Cugat del Vallés: Massilia, 2008, pp. 141 y 142.
} 
Entenderemos aquí horizonte en un sentido práctico, como aquella "horizontal que pasa por el punto de vista [del observador]" $" 12$, definiendo así una superficie horizontal perpendicular al plano del cuadro. A pesar de ello, no podemos dejar de considerar la idea de horizonte planteada por Gadamer, por ser el más pertinente a nuestros propósitos, al situarla en un ámbito cultural más amplio: "Todo presente finito tiene sus límites. El concepto de la situación se determina justamente en que representa una posición que limita las posibilidades de ver. Al concepto de la situación le pertenece esencialmente el concepto de horizonte. Horizonte es el ámbito de visión que abarca y encierra todo lo que es visible desde un determinado punto" ${ }^{\text {"13 }}$. Ambas nociones son atingentes a nuestro argumento, ya que como veremos más adelante, inevitablemente terminaran por encontrarse en el modo en que los comprendía Le Corbusier.

Una conocida frase tomada de Hacía una arquitectura nos puede ayudar a avanzar hacia la comprensión que Le Corbusier tenía de la noción de horizonte: "El hombre ve las cosas de la arquitectura con ojos que están a un metro setenta del suelo. Sólo se puede contar con objetivos accesibles al ojo, con intenciones que utilizan los elementos de la arquitectura" ${ }^{\prime 14}$.

En El Modulor, refiriéndose a la arquitectura del Renacimiento, la cual a su juicio se alejaba de los datos del problema -"la visión del ojo"- señalaba que: "Su sistema se instalaba fuera de la interpretación de la percepción visual y quienes hoy contemplan la obra no pueden tener contacto [con ella] porque le falta dicha interpretación visual con las intenciones subjetivas que se pretende haber cumplido. Cuando cierra los ojos y se absorbe en la consideración de todas las posibilidades, el hombre abstrae. Si construye es con los ojos abiertos; mira con sus ojos -que son dos y no diez, o ciento o mil- y están colocados delante de la cabeza, en la frente, la de él, mirando hacia adelante y no pudiendo ver, por tanto, ni de costado ni de espaldas, ni apreciar la esfera que le rodea, deslumbrante de las combinaciones que brotan de los poliedros filosóficos. La arquitectura se juzga con los ojos que ven, con la cabeza que gira, con las piernas que andan. [...] El ojo humano no es el de una mosca, situado en el corazón de un poliedro, sino en el cuerpo de un hombre, a uno y otro lado de la nariz y a una altura media de 1,60 m el suelo. Tal es el aparato que disponemos para apreciar la sensación arquitectónica. El cono visual está adelante, concentrado en un campo material, limitado en la realidad, y limitado también en el espíritu que tras el aparato físico, ni interpreta, ni aprecia, ni mide lo que no tiene tiempo de captar ${ }^{15}$.

La cita lo deja bastante más claro: la arquitectura, y lo que interesa a la arquitectura, se aprecia desde una altura en que se encuentran los ojos, un metro y sesenta centímetros del suelo, cuando el hombre se encuentra de pie y camina. Pero no sólo eso, allí también se reconoce que el cono visual, propio de la forma de ver del ser humano, se encuentra limitado en la realidad material, y que la mirada y el espíritu sólo pueden concentrarse en aquello que efectivamente pueden captar. Cabe preguntarse, entonces, por ese límite que define lo visible y lo separa de aquello que no se puede captar, que no se puede medir ni apreciar. ¿Dónde encontrar ese límite, sino en el horizonte que dibuja para nosotros el 'campo material' del mundo real? El horizonte entendido pues, aunque en la cita Le Corbusier no lo dice textualmente, como ese límite perceptual, inherente a quien sólo tiene dos ojos dispuestos a uno y otro lado de la nariz, montados en una cabeza que gira, además de dos piernas que le permiten desplazarse: el hombre. Hasta aquí, hay un completo acuerdo entre esta comprensión de horizonte y la planteada por Gadamer.

\footnotetext{
${ }^{12}$ Panofsky, Erwin. La perspectiva como forma simbólica. Barcelona: Fabula Tusquets Editores, 1999, p. 12.

${ }^{13}$ Gadamer, Hans-Georg. Verdad y Método. Salamanca: Ediciones Sígueme, 1999, p. 372. El destacado no es nuestro.

${ }^{14}$ Le Corbusier. Hacia una arquitectura. Op. cit, p. 143.

${ }^{15}$ Le Corbusier. El Modulor. Barcelona: Editorial Poseidón, 1976, p. 70.
} 
Pero para confirmar esta dimensión del problema, se puede consultar un pasaje del Poema del Ángulo Recto, donde Le Corbusier lo plantea en forma lírica: "El universo de nuestros ojos descansa sobre una meseta orillada de horizonte. El rostro vuelto hacia el cielo. Consideramos el espacio inconcebible hasta aquí inalcanzado. Reposar tenderse dormir - morir. La espalda al suelo... iPero me puse de pie! Puesto que eres recto hete alli listo para los actos. Recto sobre la meseta terrestre de las cosas incomprensibles tú contraes con la naturaleza un pacto de solidaridad: ese es el ángulo recto. De pie frente al mar vertical hete alli de pie"16.
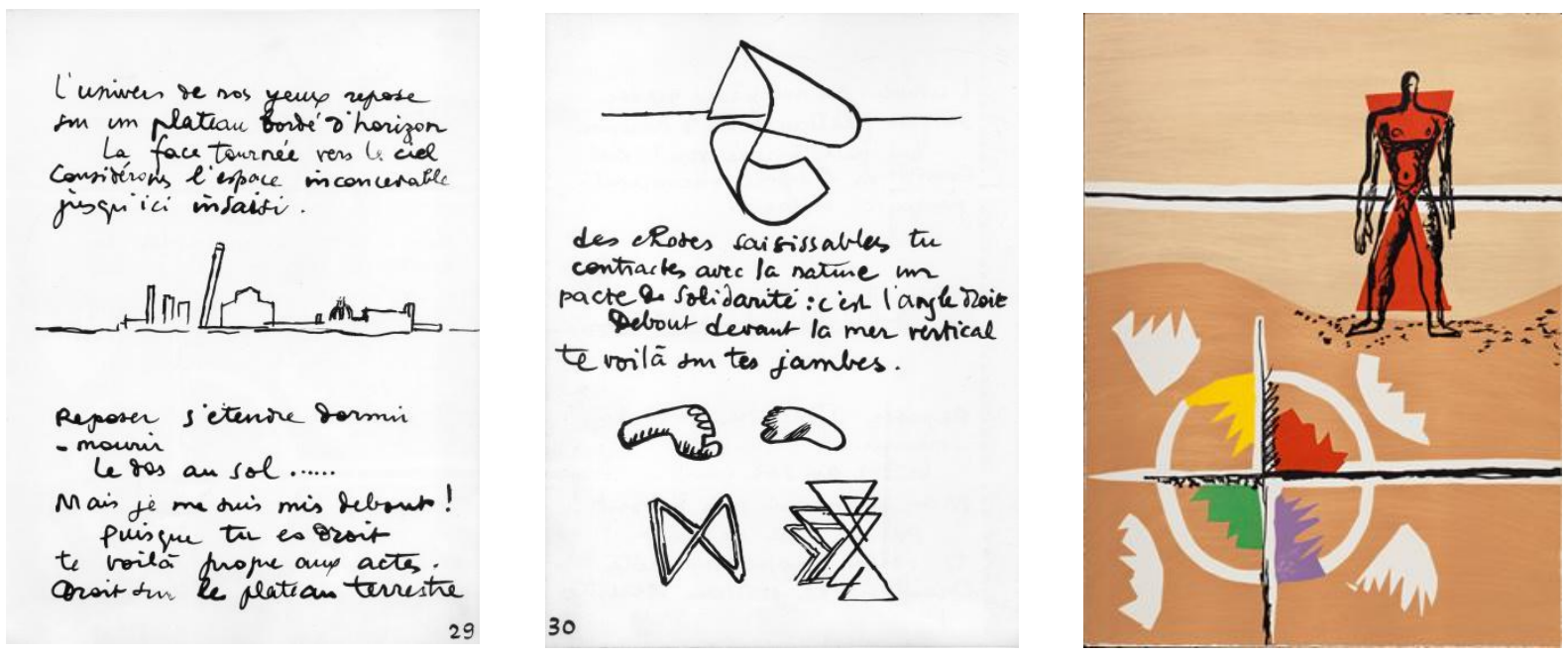

3. Le Corbusier. Poema del Ángulo Recto. A3 Milieu. Izquierda a derecha, páginas 29, 30, y 31.

El texto, para más señas, va acompañado de tres imágenes bien distintas entre sí, en su naturaleza y sentido (Figura 3). La primera, muestra la silueta de un conjunto de edificios de variada morfología, dispuestos sobre una línea horizontal, vistos de frente y desde la lejanía (Figura 3. Izquierda). Se trata precisamente de una agrupación de edificios que nos hace recordar sus dibujos juveniles, de vistas amplias y trazadas como pura silueta $^{17}$, es "una meseta orillada de horizonte". La segunda imagen (Figura 3. Centro), muy diferente a la anterior, es un diagrama compuesto por varios dibujos; el primero y más grande, que se sobrepone a una línea horizontal, es una suerte de cinta de Moebius representada tridimensionalmente; más abajo, hay dibujadas dos plantas de pies enfrentadas y dos esquemas con variaciones del símbolo del infinito. La última (Figura 3. Derecha), es una composición más compleja y acabada, claramente ilustrativa de la temática del poema. En ella vemos a un hombre de frente y de pie, parado sobre un suelo sinuoso que parece ser la orilla de una playa. Tras el hombre, y a la altura de su pelvis, cruza una línea horizontal que coincide con la altura de los ojos de quien observa la imagen. El hombre tiene inscrito sobre su cuerpo el símbolo del infinito, representado a través de dos triangulo rojos unidos por sus vértices. Sin duda, es el hombre que protagoniza el poema, aquel que se ha puesto de pie y ha hecho el pacto de solidaridad con la naturaleza, formalizado en el ángulo recto, el cual por su parte yace a sus pies trazado sobre el suelo. Ya no pueden quedar dudas sobre la noción de horizonte en Le Corbusier.

\footnotetext{
${ }^{16}$ Le Corbusier. El Poema del Ángulo Recto. Santiago de Chile: Universidad Finis Terrae, 2006, pp. 29-30. Traducción de Hernán Marchant. El poema en el francés original es el siguiente: A.3 Milieu. "L'univers de nos yeux repose sur un plateau bordé d'horizon. La face tournée vers le ciel. Considérons l'espace inconcevable jusqu'ici in saisi. Reposer s'étendre dormir -mourir. Le dos au sol... Mais je me suis mis debout! Puisque tu es droit te voilà propre aux actes. Droit sur le plateau terrestre des choses saisissables tu contractes avec la nature un pacte de solidarité: c'est l'angle droit. Debout devant la mer vertical te voilà sur tes jambes".

${ }^{17}$ La vinculación de este tipo de vistas, dibujadas por Le Corbusier en sus viajes de juventud, y sus posteriores pinturas puristas la encontramos en Silver, Kenneth E. Esprit de Corps. The Art of the Parisian Avant-Garde and the Frist World War, 1914-1925. London: Thames and Hudson, 1989.
} 
Aun así, en uno de sus artículos, Robin Evans aporta un antecedente más a este argumento. Refiriéndose al desinterés de Mies van der Rohe por el problema del horizonte, señalaba: "sin embargo, resulta significativo que Le Corbusier, quien proclamaba la línea horizontal de visión como un rasgo esencial de hombre, desestimó el doble de la altura del Modulor (366 centímetros) en interiores, explicando que quería evitar la equiparación del suelo y el techo" ${ }^{\prime 18}$.

A pesar de ser ésta una referencia indirecta, ya que el crítico la recibió de un antiguo colaborador de Le Corbusier, nos permite confirmar dos cuestiones de las que ya hemos hablado y además señalar una nueva. En relación a lo primero, el valor que Le Corbusier le confería al horizonte es algo real; segundo, que comprendía la noción de horizonte como una dimensión primordial del hombre; y por último, que Le Corbusier evitaba la organización visual preconcebida y única, desestimando la introducción de variables abstractas.

Diferenciar con claridad entre las áreas correspondientes a cielo y suelo en una imagen y en la arquitectura, no es más que la intención de establecer con radicalidad un sentido de orientación particular, precisa, circunstancial. Todo lo contrario de lo que Robin Evans observa en el Pabellón de Barcelona, donde además "es casi imposible escapar del plano de simetría [horizontal]"19, siendo la única manera de evitarlo, cambiar de posición, agachándose, sentándose, etc.

De los antecedentes aportados por Evans, es posible deducir que en el Pabellón de Barcelona el horizonte es un dato previo, dado, implícito en la simetría horizontal que lo ordena como producto de su altura $(312 \mathrm{~cm})$ y de las cantarías que acusan la altura media $(156 \mathrm{~cm})$. En Le Corbusier en cambio, al evitar esta equivalencia, el horizonte será siempre consecuencia de las múltiples posiciones que puede adoptar el hombre en relación al paisaje. Tal como lo sugiere el Poema del Ángulo Recto, el horizonte para Le Corbusier es el primer componente que permite al hombre sellar el 'pacto de solidaridad' con la naturaleza. El Horizonte, por tanto, se construye, se conquista, articulando el horizonte visual, propio de la forma de percibir del ser humano y el horizonte real, dado, propio de la naturaleza y del entorno construido; es decir, el que se nos presenta en el primer dibujo que acompaña al poema A3, y que identificamos como una meseta orillada de horizonte.

En este sentido, el mismo Modulor, como sistema dimensional, podría ser entendido como un estudio de plataformas que permiten definir horizontes precisos. En términos prácticos, se trata de definir alturas desde donde captar la realidad visual intencionalmente. En términos de Gadamer, se trataría de planos que sitúan y permiten definir posiciones desde donde comprender el mundo.

\footnotetext{
${ }^{18}$ Evans, Robin. "Las simetrías paradójicas de Mies van der Rohe”, en su Traducciones, Girona: Editorial Pre-Textos, 2005, p. 277. Allí se indica como fuente Jerzy Soltan, un antiguo colaborador de Le Corbusier.

${ }^{19}$ Evans, Robin. Op. cit., p. 275.
} 

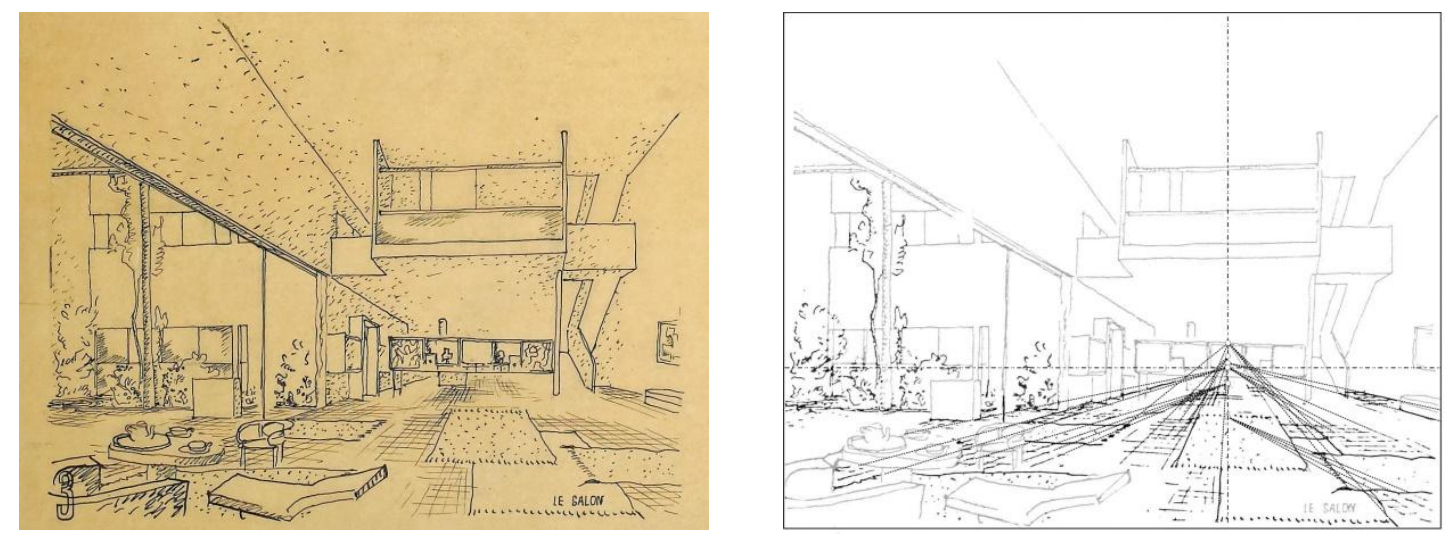

4. Izquierda. Le Corbusier. Dibujo del salón de la Villa Meyer. Derecha. Víctor Velázquez. Trazado del horizonte y puntos de fuga sobre el dibujo de Le Corbusier de la Villa Meyer.

Finalmente, hay un último antecedente que permite comprender con mayor precisión la noción de Horizonte en Le Corbusier, tanto en un sentido práctico como cultural. De acuerdo a lo señalado por Víctor Velásquez, la técnica que Le Corbusier probablemente utilizaba para dibujar algunas vistas de sus proyectos consistía en calcar o copiar una perspectiva cónica previamente ejecutada con instrumentos ${ }^{20}$. Realizando un riguroso análisis de un dibujo del interior de Villa Meyer (Figura 4. Izquierda), Víctor Velásquez demuestra los calces y descalces entre la perspectiva cónica que sirvió como base y el dibujo que finalmente trazó encima Le Corbusier. Una de sus conclusiones, desde mi punto de vista quizás la más significativa, es que el dibujo trazado a mano respetó casi todas las referencias definidas por la perspectiva, con excepción del punto de fuga único, ya que se trata de una perspectiva centralizada. Como consecuencia, algunos elementos, particularmente los muebles más cercanos al observador, se proyectan a puntos de fuga diversos, distintos de aquel que organiza la imagen. Lo curioso de estos descalces es que la disposición de estos nuevos puntos no es arbitraria. Casi todos confluyen en la línea vertical que, en el plano geometral, define la posición del observador. Más curioso aún es que estos puntos no se alejan demasiado de la línea del horizonte, situándose sobre o bajo ella (Figura 4. Derecha).

Lo importante, para nosotros, es que estos sucesivos puntos de fuga, dispuesto en vertical, generan una dilatación del horizonte en esa misma dirección, produciendo una suerte de ventana: un área que permite el acomodo de los distintos elementos que buscan su referente en 'otros' horizontes. Se podría decir que se trata de un horizonte que vibra, en su intento de introducir en "un espacio totalmente racional, es decir, infinito, constante, y homogéneo "21 , propio de la perspectiva renacentista, una dimensión propia de la percepción humana.

\footnotetext{
${ }^{20}$ Velásquez, Víctor: “Un Dibujo de la Villa Meyer”. En Massilia. Annuaire d'Etudes Corbuseennes. Sant Cugat del Vallés: Associacio d'Idees, Centre d'Investigacions Estètiques, p. 71.

${ }^{21}$ Panosfky, Erwin. Op. cit., p. 12 y ss.
} 


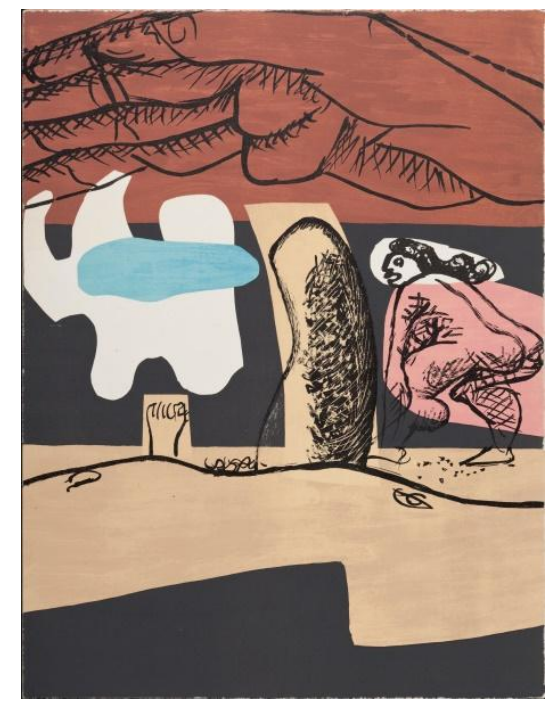

5. Le Corbusier. Poema del Ángulo Recto. C2 Chair, página 85.

En el caso de Le Corbusier, no hablamos pues del horizonte como una línea, como lo establece canónicamente la perspectiva renacentista, sino como un área que recuerda el esquema en espina de pez con que Panofsky explica la perspectiva angular de la antigüedad ${ }^{22}$. Esta comprensión del horizonte, como un 'línea' expandida, se ve confirmada en otra imagen del Poema del Ángulo Recto ${ }^{23}$ (Figura 5). En ella, un hombre aparentemente recostado en la playa mira hacia la costa por sobre su propio cuerpo, defiendo un área rectangular de contemplación que queda contenida entre su vientre y la mano derecha que utiliza como visera ${ }^{24}$. El área en cuestión es enfatizada por un fondo negro, sobre el cual se recortan: el muslo derecho y parte del pie izquierdo del hombre que está tendido, el cuerpo de una mujer, probablemente la que motiva el poema. Es decir, se concentran en esta área los elementos que constituyen el límite visual próximo, humano, que se contrapone al límite más extremo, pero aun así posible de percibir de la naturaleza. Esta situación representada en la imagen es descrita elocuentemente en la parte final del poema, C2 Chair: "Pasa la mujer. ¡Oh, yo dormía, perdóneme! Con la esperanza de capturar la suerte tendí la mano... El amor es una palabra sin frontera. Es también una creación humana un ensayo un intento" ${ }^{„ 25}$. Tanto la imagen como el poema son, pues, un llamado de atención sobre aquello que se ha identificado como "la superación de los sentidos a ras de tierra -el olfato y el oído-, desplazados por la hegemonía del sentido de la distancia: la mirada; y cerrando el círculo, la combinación entre ojo y mano",26.

\footnotetext{
${ }^{22}$ Panofsky, Erwin. Op. cit., pp. 22-23.

${ }^{23}$ Le Corbusier. El Poema del Ángulo Recto. Op. cit., p. 85.

${ }^{24}$ Robin Evans, asertivamente refiere un gesto similar, a propósito de un autorretrato de Joshua Reynolds. En el cuadro, vemos al pintor sosteniendo sus instrumentos de trabajo con la mano derecha, mientras que la otra la utiliza como visera para protegerse de los potentes rayos del sol, en su afán de otear la lejanía. ¿Qué hace esa mano sino replicar el horizonte por medios humanos? Evans, Robin. Op. cit., pp. 266-267.

${ }^{25}$ Le Corbusier. El Poema del Ángulo Recto. Op. cit., p. 84. En el original: "!Passe la femme. Oh je dormais excusez-moi; Avec l'espoir de saisir la chance j'ai tendu la main... L'amour est un mot sans frontière. C'est aussi c'est encore une création humaine un essai une entreprise.

${ }^{26}$ Quetglas, Josep. "La línea vertical". En AA.VV: Le Corbusier y la síntesis de la artes. El Poema del Ángulo Recto. Madrid: Círculo de Bellas Artes, 2006, p. 54.
} 


\section{La noción de horizonte en la generación de la arquitectura}

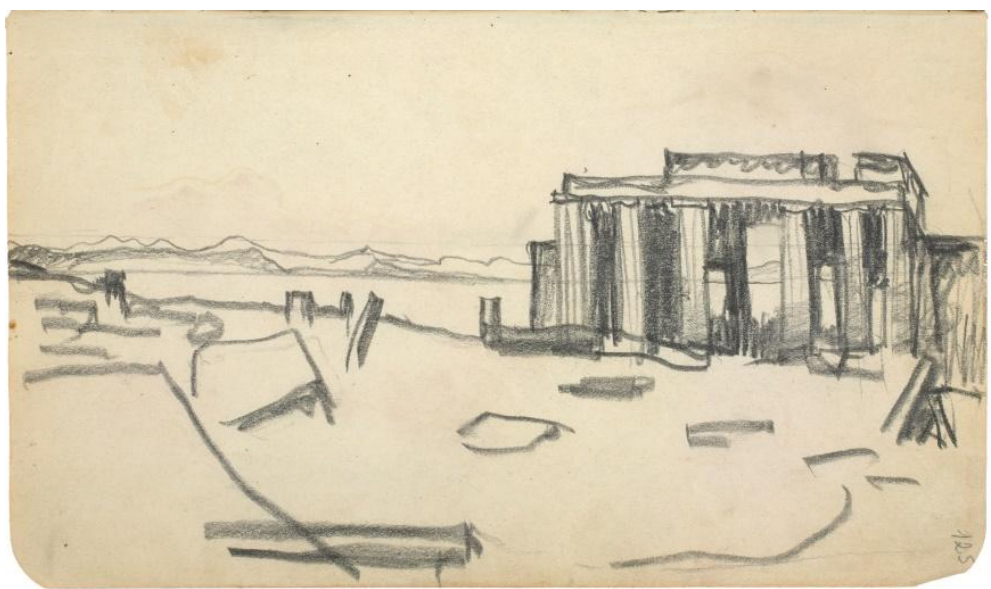

6. Ch-É. Jeanneret. Acrópolis de Atenas. Los Propileos vistos desde el Erecteion, 1911.

Un dibujo de las ruinas de los Propileos, realizado por Le Corbusier en 1911 es revelador de cuando hasta ahora hemos expuesto (Figura 6). Los elementos que lo componen se ordenan a partir de la coordinación del horizonte "visual", propio de la mirada del observador, con el horizonte "real", límite que delinea el encuentro de la tierra con el mar en la lejanía. Como ya se ha dicho, el horizonte en Le Corbusier es una entidad que representa la coordinación visual entre observador y mundo, que además estructura el dibujo en términos formales, constituyendo su fundamento. En ello radica su importancia.

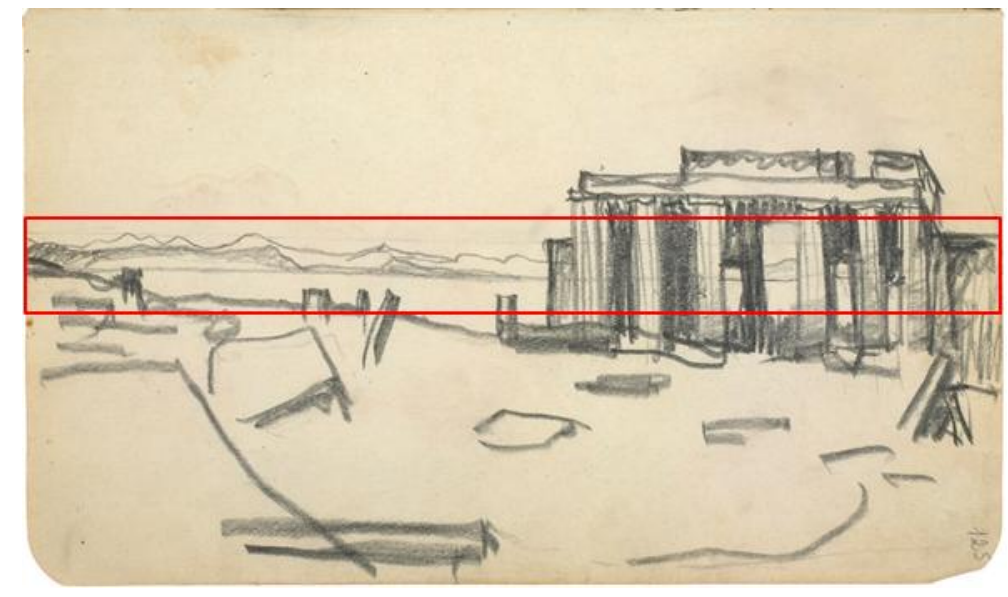

7. Horizonte "real" expandido verticalmente.

Si esa línea horizontal, como ya hemos sugerido a propósito de las imágenes anteriores, fuese expandida verticalmente, configuraría un área rectangular que corresponde a esa porción de mundo que se ve con mayor nitidez y precisión, y que en consecuencia acapara el principal interés del observador (Figura 7). Dicho así, el área en cuestión se puede entender como el lugar donde la mirada se detiene, atrapada por una figura que la modela, pero que sin embargo puede traspasar: una gran ventana de forma horizontal. 


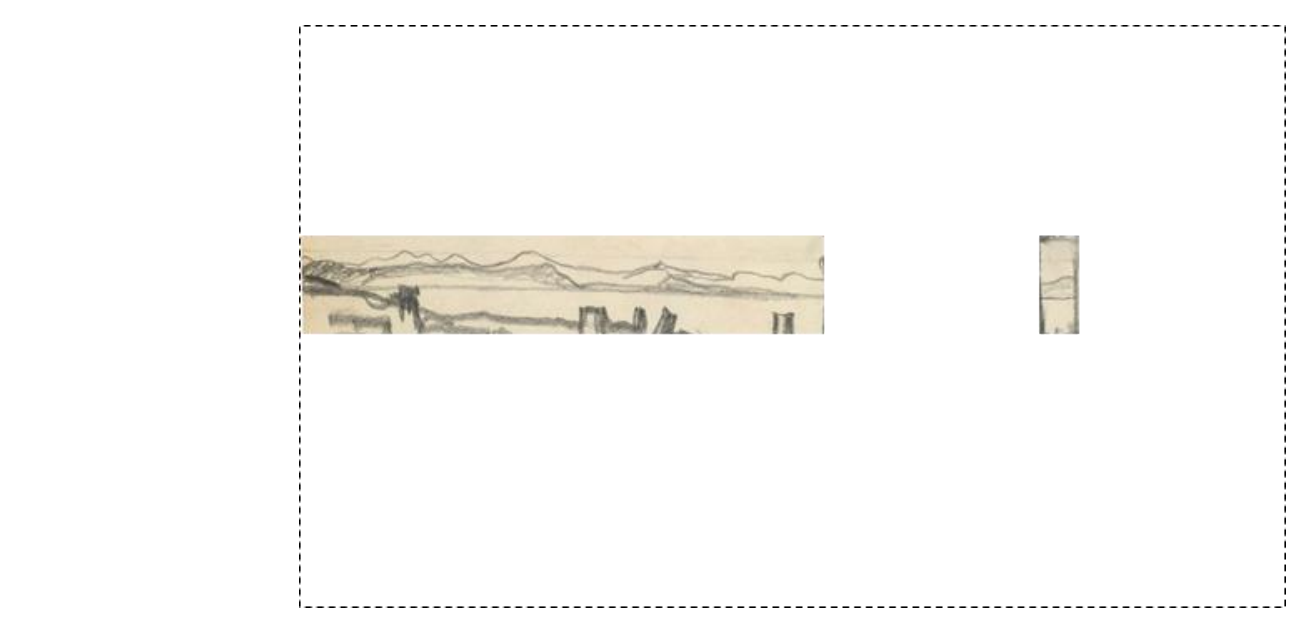

8. Recorte de ventanas en el horizonte expandido.

Pero si la miramos con mayor detención, esta área se puede reducir a dos ventanas (Figura 8): una menor, conformada por el umbral central que definen las ruinas de los propileos, que atrae la mirada puntualmente y a través de la cual ésta avanza dimensionando la profundidad del paisaje; y una mayor, mucho más amplia, situada a la izquierda de las ruinas, donde la mirada en principio reposa, para después desplazarse, siguiendo la silueta de las colinas lejanas.

En esta observación, la arquitectura o sus restos son utilizados como un dispositivo para aproximarse visualmente al paisaje. A través de ella se mide el paisaje, y la lejanía cobra un nuevo sentido al ser contrastada con los elementos construidos, más próximos al observador. Lejanía, elementos construidos y observador, llegan a ser uno en el dibujo. El observador, y dibujante, queda así, situado en relación al mundo que lo envuelve.

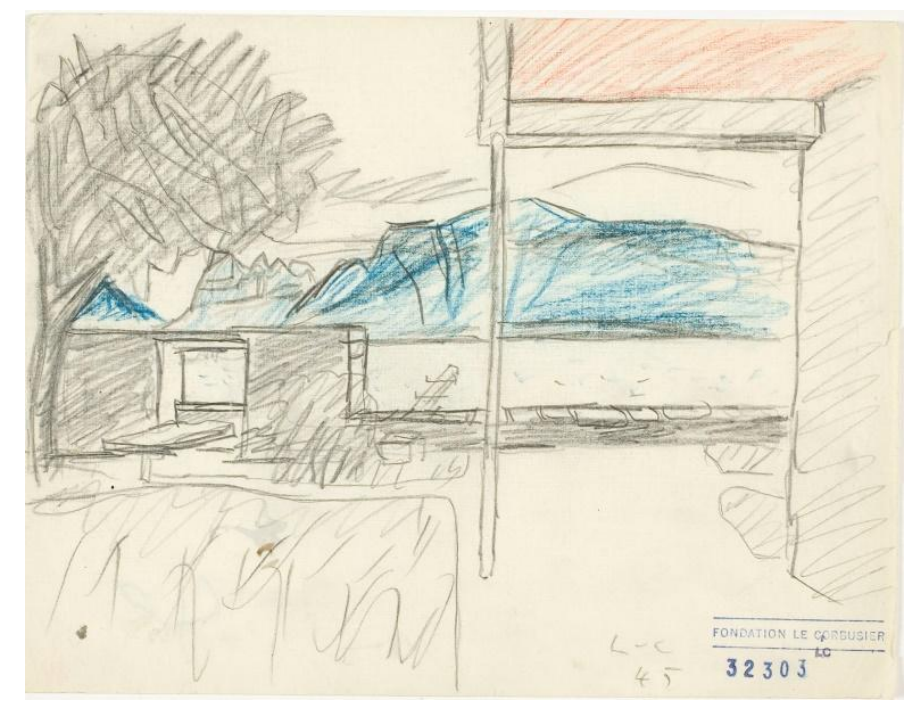

9. Le Corbusier. Patio de la Petit Maison, 1945.

Le Corbusier desarrolló literalmente esta observación una década más tarde, en la pequeña casa que proyectó para sus padres en la orilla del Lago Leman. Lo confirma una serie de dibujos que realizó muchos años después de haberse construido la casa y que publicó en 1954, en el libro Une Petite Maison ${ }^{27}$. Uno de los dibujos (Figura 9) hace patente este problema al mostrar el encuadre del paisaje a través del muro que se abre extensamente

\footnotetext{
${ }^{27}$ Le Corbusier. Une Petite Maison. Zurich: Editions Girsberger, 1954. Traducción española, Una Pequeña Casa. Buenos Aires: Ediciones Infinito, 2008, pp. 72-73.
} 
hacia la derecha y puntualmente en la ventana junto al árbol, tal como las ruinas encuadraban el paisaje, en el dibujo que había hecho en Atenas en 1911.

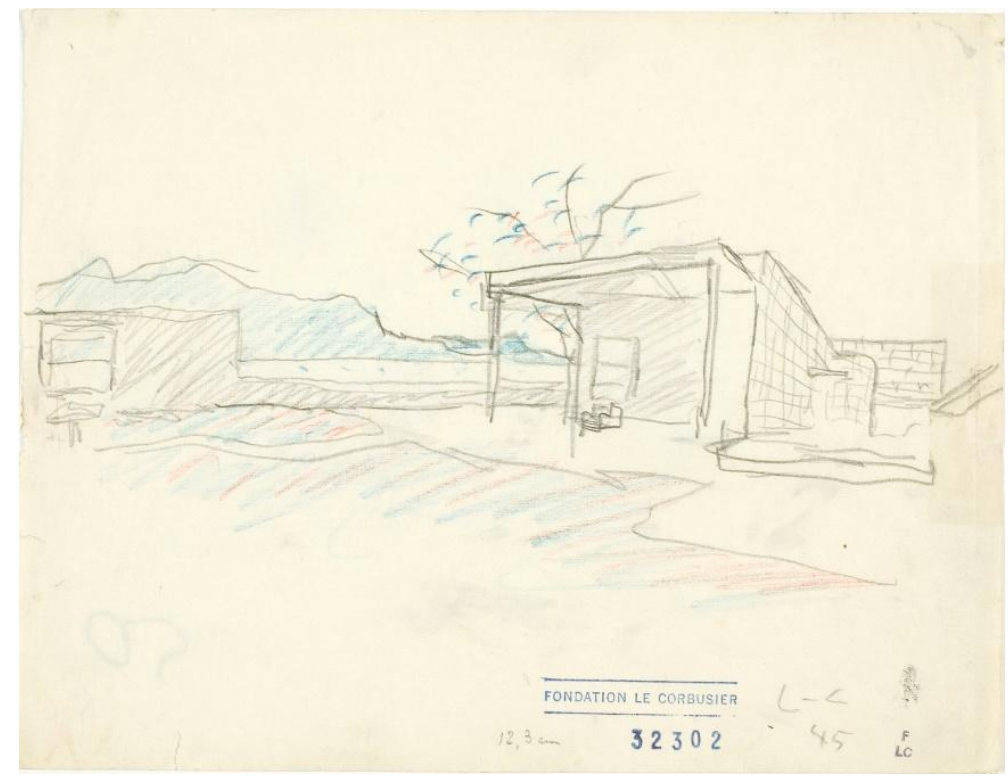

10. Le Corbusier. Patio de la Petit Maison visto en escorzo desde la izquierda, 1945.

Un segundo dibujo (Figura 10), muestra la misma escena pero vista en escorzo desde la izquierda, extremando completamente el ángulo de visión, para evidenciar el modo en que el lago y la montaña pasan por detrás del muro, y cómo una porción de ellos queda atrapado en la ventana cuadrada. En este segundo dibujo, a diferencia del anterior, el horizonte visual del observador coincide con el horizonte real, que en este caso tiene correspondencia con la línea donde se encuentran el lago y la montaña. De acuerdo a estas referencias, el dibujo permite visualizar la situación de la casa y el muro que la envuelve, en relación al paisaje lejano y a la posición del observador.

Por último, un diagrama (Figura 11) hace explícita la presencia del horizonte y del ángulo recto como fundamento de la situación de la casa frente al paisaje. En esta imagen, aparentemente, la vertical es asumida por el delgado pilar que sostiene el alero que cubre la terraza, tal como se muestra en los dos dibujos de la casa que hemos comentado.

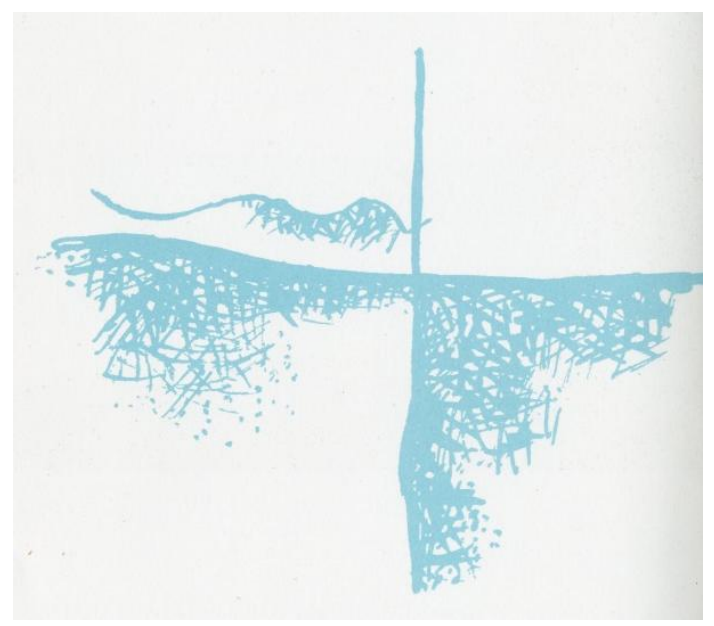

11. Le Corbusier. Diagrama del “Ángulo Recto” aplicado a la Petit Maison, 1945. 


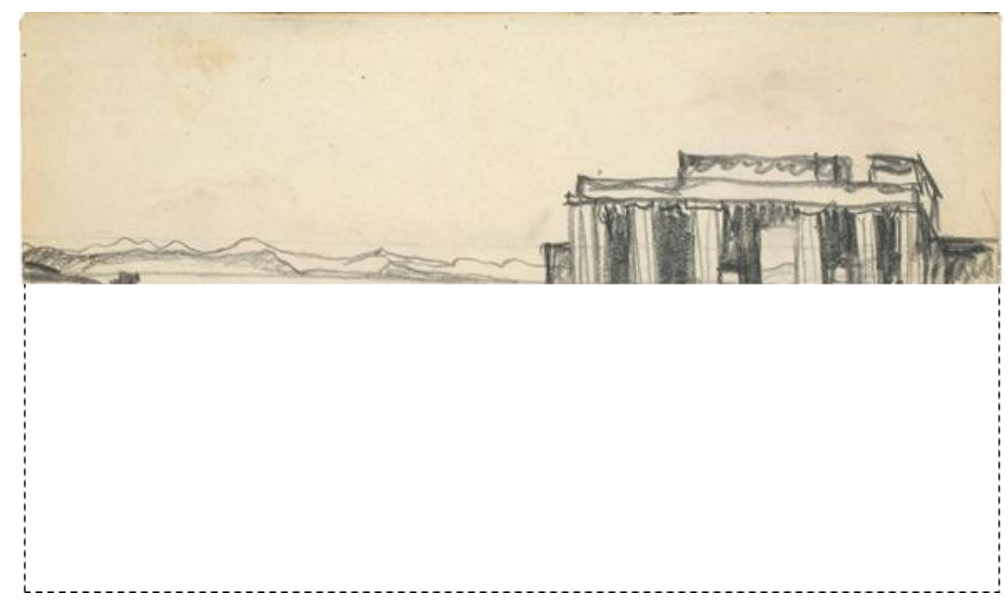

12. Área visible sobre la línea del horizonte.

Por otro lado, si volvemos a mirar el mismo dibujo (Figura 12) y consideramos ahora el horizonte "real" no como una ventana, sino como una línea que determina un arriba y un abajo, el cielo y la tierra o cielo y el mar, encontraremos una segunda observación, que está claramente vinculada con el primer dibujo que hemos comentado del poema A3 del Poema del Ángulo Recto. Esta observación trata del tema del "coronamiento" y se construye por medio del ocultamiento del suelo próximo y lejano, impidiendo ver de dónde emerge lo visible y, por tanto, dimensionar el distanciamiento entre lo lejano, lo cercano, y el observador. De este modo, vemos que la parte superior del dibujo descansa ahora sobre una tensa línea horizontal, sobre la cual se dibujan simultáneamente, como si de un ejercicio de comparaciones se tratara, lo que corona la corteza terrestre y lo que corona la arquitectura.

Como es sabido, en torno a este tema, en esencia de comparaciones de atributos y de contrastes, entre elementos naturales y construidos que intercambian posiciones, Le Corbusier realizó una serie de ejercicios proyectuales y de obras concretas en los que los materializó. Quizás entre las más evidentes está el ático De Beistegui, de 1930, y la cubierta de la Unidad Habitacional de Marsella, entre otros ${ }^{28}$. El medio para ponerlo en práctica es siempre el mismo: un muro que encierra parcialmente un espacio, el cual, de acuerdo a su altura o sus perforaciones, oculta o deja ver el paisaje circundante. Es decir, la arquitectura, al igual que los dibujos, es la que permite situar a los usuarios en su entorno, revelando y construyendo -a la vez- la situación de estar en ese lugar en particular.

\section{Conclusión}

Podemos concluir subrayando tres aspectos sobre lo ya dicho:

Primero, que en Le Corbusier el dibujo es un instrumento que le permitió situarse con precisión frente al mundo dado; y luego nos ha permitido a nosotros, simples espectadores, situarnos del mismo modo ante la realidad que observó y dibujó.

Segundo: que en este reconocerse frente al mundo dado, la noción de horizonte fue fundamental ya desde sus experiencias de juventud, incluyendo incluso su viaje a Italia de 1907. Y que, más tarde, la noción horizonte

\footnotetext{
${ }^{28}$ Ricardo Daza, propuso una observación similar al comparar la cubierta de la Unidad de Habitación de Marsella con un dibujo realizado en Delfos, durante el viaje a Oriente. Daza, Ricardo. "Paisaje Homérico. La Unidad de Habitación de Marsella”. En Cuadernos de Extensión. Semana de Le Corbusier 17-20 mayo 2011. Santiago de Chile: Escuela de Arquitectura UC, 2011, pp. 89-92.
} 
también fue fundamental en su comprensión de la arquitectura, siendo parte fundamental de sus proyectos, obras teóricas y construidas.

Por último, y a pesar de que sus dibujos se estructuran a partir de la línea del horizonte, ellos se distancian de la comprensión canónica, abstracta, propia de la perspectiva renacentista, al llevar esta línea más allá de su condición abstracta, geométrica, y reemplazarla por un área que da cabida a distintos puntos de fuga que se distribuyen en la vertical, aquella que define la posición del observador. Esta área, así concebida, le permitió poner en acuerdo lo cercano y lo lejano, los límites propios de la percepción humana y los límites del mundo dado; limites en tanto que, aún, pueden ser percibidos.

\section{Figuras}

Figura 1. Izquierda. Ch-É. Jeanneret. Santa Maria Novella, sarcófagos del muro del patio de ingreso, Florencia, 8 de octubre de 1907. Acuarela y tempera sobre papel. 19 x 26,6 cm. Fuente: Le Corbusier. Il Viaggio in Toscana (1907). Venecia: Cataloghi Marsilio, 1987, figura 23. Derecha. Ch-É. Jeanneret. La Acrópolis vista desde el Monte Licabeto. Lápiz grafito. 10 x $17.8 \mathrm{~cm}$. Ch-E. Jeanneret / Le Corbusier. Voyage d'Orient. Carnets. Milano: Electa; Paris: Fundation Le Corbusier, 2002, Carnet 3, p. 98.

Figura 2. Ch-É. Jeanneret. Vista de la Cúpula de Santa María de las Flores y del Palacio Viejo. Florencia, primeros días de octubre de 1907. Acuarela sobre papel. 17,5 x 13,6 cm. Fuente: Le Corbusier. Il Viaggio in Toscana (1907). Venecia: Cataloghi Marsilio, 1987, figura 44.

Figura 3. Le Corbusier. El Poema del Ángulo Recto. Poema A3 Milieu. Izquierda a derecha, páginas 29, 30, 31.Fuente: Le Corbusier. El Poema del Ángulo Recto. Santiago de Chile: Universidad Finis Terrae, 2006.

Figura 4. Izquierda. Le Corbusier. Dibujo del salón de la Villa Meyer. Derecha. Víctor Velázquez. Trazado del horizonte y puntos de fuga sobre el dibujo de Le Corbusier de la Villa Meyer. Fuente: Velásquez, Víctor: "Un Dibujo de la Villa Meyer". En Massilia. Annuaire d'Etudes Corbuseennes. Sant Cugat del Vallés: Associacio d'Idees, Centre d'Investigacions Estètiques. 2002, pp. 71-87.

Figura 5. Le Corbusier. Poema del Ángulo Recto. C2 Chair. Fuente: Le Corbusier. El Poema del Ángulo Recto. Santiago de Chile: Universidad Finis Terrae, 2006, p. 85.

Figura 6. Ch-É. Jeanneret. Acrópolis de Atenas. Los Propileos vistos desde el Erecteion. Lápiz grafito. 10 x 17.8 cm. Fuente: Ch-E. Jeanneret / Le Corbusier. Voyage d'Orient. Carnets. Milano: Electa; Paris: Fundación Le Corbusier, 2002, Carnet 3, p. 125.

Figura 7. Horizonte expandido verticalmente. Elaboración del autor (Figura 6 intervenida).

Figura 8. Recorte de ventanas en el horizonte expandido. Elaboración del autor (Figura 6 intervenida).

Figura 9. Le Corbusier. Patio de la Petit Maison, 1945. Fuente: Le Corbusier. Une Petite Maison. Zurich: Editions Girsberger, 1954. Traducción española: Una Pequeña Casa. Buenos Aires: Ediciones Infinito, 2008, pp. 72-73.

Figura 10. Le Corbusier. Patio de la Petit Maison visto en escorzo desde la izquierda, 1945. Fuente: Le Corbusier. Une Petite Maison. Zurich: Editions Girsberger, 1954. Traducción española: Una Pequeña Casa. Buenos Aires: Ediciones Infinito, 2008, p. 71.

Figura 11. Le Corbusier. Diagrama del “Ángulo Recto” aplicado a la Petit Maison, 1945. Fuente: Le Corbusier. Une Petite Maison. Zurich: Editions Girsberger, 1954. Traducción española: Una Pequeña Casa. Buenos Aires: Ediciones Infinito, 2008, p. 58.

Figura 12. Área visible sobre la línea del horizonte. Elaboración del autor (Figura 6 intervenida).

\section{Bibliografía}

Daza, Ricardo. "Paisaje Homérico. La Unidad de Habitación de Marsella". En Cuadernos de Extensión. Semana de Le Corbusier 17-20 mayo 2011. Santiago de Chile: Escuela de Arquitectura UC, 2011, pp. 77-93. 
Evans, Robin. "Las simetrías paradójicas de Mies van der Rohe", en su Traducciones. Girona: Editorial PreTextos, 2005, pp. 246-289.

Gadamer, Hans-Georg. Verdad y Método. Salamanca: Ediciones Sígueme, 1999.

Hidalgo, Germán. La Arquitectura del Croquis. Dibujos de Ch-E. Jeanneret en Italia 1907 y en Oriente 1911. Un estudio de sus antecedentes. Universidad Politécnica de Cataluña, Escuela Técnica Superior de Arquitectura de Barcelona, Departamento de Composición, 2000. Tesis doctoral inédita.

Hidalgo, Germán. "La constatación de un aprendizaje. El viaje a Italia de 1907 de Ch-É. Jeanneret”. Massilia, Annuaire d'Etudes Corbuseennes. Sant Cugat del Vallés: Associacio d'Idees, Centre d'Investigacions Estètiques, 2008, pp. 04-30.

Jeanneret, Charles-Édouard (Le Corbusier) El Viaje de Oriente. Murcia: Colegio Oficial de Aparejadores y Arquitectos Técnicos. Librería Yerba, 1993.

Le Corbusier. Hacia una arquitectura. Barcelona: Editorial Apóstrofe, 1998.

Le Corbusier. El Modulor. Barcelona: Editorial Poseidón, 1976

Le Corbusier. El Poema del Ángulo Recto. Santiago de Chile: Universidad Finis Terrae, 2006. Traducción Hernán Marchant.

Le Corbusier. Une Petite Maison. Zurich: Editions Girsberger, 1954. Traducción española: Una Pequeña Casa. Buenos Aires: Ediciones Infinito, 2008.

Le Corbusier. Il Viaggio in Toscana (1907). Venecia: Cataloghi Marsilio, 1987.

Monsteys, Xavier. "El hombre que veía amplios horizontes: Le Corbusier el paisaje y la tierra". En Massilia. Annuaire d'Etudes Corbuseennes. Sant Cugat del Vallés: Associacio d'Idees, Centre d'Investigacions Estètiques, 2004 (bis). pp. 6-21.

Panofsky, Erwin. La perspectiva como forma simbólica. Barcelona: Fabula Tusquets Editores, 1999.

Quetglas, Josep. "La línea vertical”. En AA.VV: Le Corbusier y la síntesis de la artes. El Poema del Ángulo Recto. Madrid: Círculo de Bellas Artes, 2006, pp. 51-57.

Quetglas, Josep. Les Heures Claires. Proyecto y arquitectura en la Villa Savoye de le Corbusier y Pierre Jeanneret. Sant Cugat del Vallés: Massilia, 2008.

Ruskin, John. The Elements of Drawing. London: George Allen, 1856. Traducción Española: Técnicas de dibujo. Barcelona: Editorial Leartes, 1999.

Seckler, Mary Patricia May. The Early Drawing of Charles-Édouard Jeanneret (Le Corbusier) 1902-1908. New York and London: Garland Publishing, 1977.

Silver, Kenneth E. Esprit de Corps. The Art of the Parisian Avant-Garde and the Frist World War, 1914-1925. London: Thames and Hudson, 1989.

Velásquez, Víctor: “Un Dibujo de la Villa Meyer”. En Massilia. Annuaire d'Etudes Corbuseennes. Sant Cugat del Vallés: Associacio d'Idees, Centre d'Investigacions Estètiques. 2002, pp. 71-87. 